\title{
The role of invariant natural killer T cells in microbial immunity
}

\author{
Yuki Kinjo ${ }^{1}$, Naoki Kitano ${ }^{1}$, and Mitchell Kronenberg ${ }^{2}$ \\ ${ }^{1}$ Department of Chemotherapy and Mycoses, National Institute of Infectious Diseases, Toyama \\ 1-23-1, Shinjuku-ku, Tokyo 162-8640, Japan \\ 2Division of Developmental Immunology, La Jolla Institute for Allergy \& Immunology, La Jolla, \\ California 92037, USA
}

\begin{abstract}
Invariant natural killer T cells ( $I N K T$ cells) are unique lymphocytes with characteristic features, such as expression of an invariant $\mathrm{T}$ cell antigen receptor (TCR) a chain, recognition of glycolipid antigens presented by CD1d molecules, and ability to rapidly produce large amounts of cytokines, including interferon- $\gamma$ (IFNY) and interleukin 4 (IL-4) upon TCR stimulation. Many studies have demonstrated that ${ }_{\mathrm{NKK}}$ cells participate in immune response against diverse microbes, including bacteria, fungi, protozoan parasites and viruses. Generally, these cells play protective roles in host defense against infections. However, in some contexts they play pathogenic roles, by inducing or augmenting inflammation. Recent reports show that NKT cells recognize glycolipid antigens from pathogenic bacteria including Streptococcus pneumoniae, and they contribute to host defense against infection. $\mathrm{INKT}$ cell responses to these microbial glycolipid antigens are highly conserved between rodents and humans, suggesting that $i$ NKT cells are evolutionally conserved because their invariant TCR is useful in detecting certain pathogens. Furthermore, glycolipid-mediated INKT cell activation during immunization has adjuvant activity, enhancing humoral and cell-mediated responses. Therefore, $\mathbb{I N K T}$ cell activation is an attractive target for developing new vaccines for infectious diseases.
\end{abstract}

\section{Keywords}

NKT cell; glycolipid; CD1d; invariant; bacteria

\section{Introduction}

Natural killer T (NKT) cells are innate-like lymphocytes that co-express both a $\mathrm{T}$ cell antigen receptor (TCR) and NK receptors [1-5]. In contrast to conventional T cells that recognize peptide antigens presented by major histocompatibility complex (MHC) class I and II molecules, NKT cells recognize glycolipid antigens presented by CD1d, an MHC class I-like antigen-presenting molecule. Crystal structure analyses show that the CD1d molecule possesses two antigen-binding grooves, called the $\mathrm{A}^{\prime}$ and $\mathrm{F}^{\prime}$ pockets $[5,6]$. These pockets are deep, narrow and hydrophobic, making them suitable for binding the lipid tails of glycolipid antigens $[5,6]$.

A major subset of NKT cells expresses an invariant TCR that uses the Va14-Ja18 gene segments in mice, and the homologous Va24-Ja18 in humans. These cells are referred to 
type I [7] or as invariant NKT ( $\mathrm{NKT}$ ) cells [1-5]. a-galactosylceramide (a-GalCer), a synthetic homologue of marine sponge-derived glycolipid, was the first $\imath$ NKT cell antigen discovered, and this highly potent glycolipid antigen has been critical for understanding the functions of these cells [8]. Upon antigen recognition, INKT cells rapidly produce large quantities of cytokines, including both interferon-Y (IFNY) and interleukin 4 (IL-4), in addition to others, and they express costimulatory molecules such as CD40 ligand (CD40L) [1-4]. Activated INKT cells can stimulate dendritic cells (DCs), NK cells and other immune cells through cytokines such as IFNy, and expression of CD40L, leading to enhancement of the innate immune response, which ultimately contributes to augmenting acquired immunity. With these unique features, $I$ NKT cells participate in mouse models of various immune and inflammatory responses including cancer immunity, microbial immunity, autoimmunity, atherosclerosis and asthma.

The $\mathrm{INKT}$ cell response to glycolipid antigens is highly conserved between human and mouse. Mouse $\mathrm{N}$ NKT cells can recognize glycolipid antigens presented by human CD1d, while human $I$ NKT cells can recognize the same antigen presented by mouse CD1d molecules [9]. This evolutionary conservation suggests that the NKT cell response also is an important immune mechanism for humans. Therefore, findings obtained from mouse studies may provide useful information for understanding the possible roles of human $\mathrm{NKT}$ cells in immune responses.

Another population of CD1d reactive NKT cells exists that expresses a more diverse TCR repertoire; these are sometimes called type II NKT cells. Sulfatide has been shown to activate some of these type II cells, and there is evidence they exert suppressive roles in experimental autoimmune encephalomyelitis, a mouse model of multiple sclerosis [10]. In contrast to the protective role of $i$ NKT cells in tumor immunity, sulfatide reactive NKT cells were shown to inhibit anti-tumor responses [11]. While new antigens for type II NKT cells are continually being discovered, the function of these cells in microbial immunity remains to be elucidated $[12,13]$.

In this review, we focus on $\mathrm{INKT}$ cells and summarize the roles of these cells in response to diverse microbes concentrating on selected examples of infections by bacteria, fungi, protozoan parasites and viruses. We describe how intestinal microbes affect $\mathrm{INKT}$ cell function and regulate inflammation. We also review recent discoveries of bacterial glycolipid antigens recognized by $\mathrm{INKT}$ cells and their importance in microbial immunity.

\section{Role of $\mathbb{N K T}$ cells in host defense against infections}

\section{Bacterial infections}

It has been shown that 1 NKT cells contribute towards host defense against a number of bacterial infections; a few examples are summarized here. Streptococcus pneumoniae is a leading cause of community acquired pneumonia and secondary bacterial pneumonia post influenza virus infection. Following pulmonary infection with $S$. pneumoniae, Ja18deficient Ja18KO mice that lack $\mathbb{N}$ NKT cells [14] had significantly higher bacterial burden in the lung and a lower survival rate compared to wild-type (WT) mice [15]. Neutrophil recruitment to the lung was impaired in Ja18KO mice in accordance with lower production of neutrophil recruiting cytokines, including tumor necrosis factor (TNF), as well as reduced macrophage inflammatory protein 2 (MIP-2). Furthermore, transfer of liver mononuclear cells (20-40\% INKT cells) from WT mice into Ja18KO mice restored neutrophil accumulation through increased production of TNF and MIP-2, resulting in bacterial clearance [16]. However, transfer of liver mononuclear cells from Ja18KO or IFNYKO mice into Ja18KO mice did not lead to recovery of neutrophil accumulation and a normal level of bacterial clearance, 
suggesting that IFNY, possibly from $i$ NKT cells, plays an important role in host defense against $S$. pneumoniae infection.

It should be noted that Ja18KO mice have recently been reported to have deficits in rearrangements of approximately $60 \%$ of their Ja segments, all of those upstream from Ja18, likely due to insertion of the gene encoding neomycin resistance during construction of the gene deficient mouse strain [17]. This raises an important caveat to assigning any defect in Ja18KOmice solely to the $\mathbb{I N K T}$ cell defect. In $S$. pneumoniae infection, however, the evidence for the involvement of $I$ NKT cells is compelling. INKT cells were strongly activated in the lung to produce cytokines such as IFNY and IL-17A within hours of infection [18], and they act to stimulate the innate immune response to protect the host within days. This rapid action is not consistent with the kinetics of a typical adaptive immune response that would be affected by altering the Ja repertoire.

INKT cells also play a role in host defense against bacterial infection through activation of DCs and induction of IFNY production by $\mathrm{CD} 4^{+}$and $\mathrm{CD} 8^{+} \mathrm{T}$ cells. In Chlamydophila (formerly called as Chlamydia) pneumoniae infection, $\mathrm{INKT}$ cells accumulated in the lungs in the early phase of infection and they expressed intracellular IFNY [19]. In Ja18KO mice, expression of CD40 and intracellular IL-12 in CD8 $\mathrm{a}^{+} \mathrm{DCs}$ and IFNY production by CD4 ${ }^{+}$ and $\mathrm{CD}^{+} \mathrm{T}$ cells were reduced compared to WT mice [20]. IL-12 production by CD8 $\mathrm{a}^{+}$ DCs is known to be dependent on IFNY and the CD40-CD40L interaction, suggesting that INKT cells may promote bacterial clearance by enhancing the Th1 response through stimulation of DCs with IFNY and co-stimulatory molecules during $C$. pneumoniae infection. Chlamydia muridarum is the mouse model for Chlamydia trachomatis infection, a sexually transmitted infection that can lead to serious damage to the female reproductive tract. The results from two recent studies indicate this organism has an antigen for $\mathrm{INKT}$ cells [21, 22], although its structure is unknown. Also, infected epithelial cells degrade CD1d, suggestive of an immune evasion mechanism [23]. Despite this, there is no consensus on the role of $i$ NKT cells in the host response to $C$. muridarum, one report suggesting that INKT cells enhance the growth of this organism by inducing a Th2 cytokine milieu [19], while other studies suggest 1 NKT cells can promote clearance of bacteria, but also immune pathology [22].

INKT cells may also play a role in preventing stroke-associated bacterial infection. Compared to WT mice, CD1dKO mice were highly susceptible to bacterial infection after transient midcerebral artery occlusion induced brain injury, a rodent model of stroke [24]. Protective liver $i$ NKT cell function was suppressed by noradrenergic neurotransmitter(s) after stroke. Blockade of this innervation provided protection from bacterial infection in WT mice but not in CD1dKO mice [24]. Furthermore, activation of $I N K T$ cells with aGalCer induced inflammatory cytokine production and prevented bacterial infections after stroke. These data suggest that stroke-associated bacterial infections may be induced by suppression of $\imath$ NKT cell function.

\section{Fungal infections}

INKT cells have been shown to play an important role in host defense against several fungal infections. For example, following pulmonary infection with Cryptococus neoformans, INKT cells accumulated in the lungs, which was dependent on the C-C motif chemokine-2 (CCL-2)/macrophage chemoattractant protein-1 (MCP-1) in the early phase of infection [25]. The Th1 response that is critical for $C$. neoformans elimination was reduced in Ja18KO mice resulting in delayed clearance of $C$. neoformans. It was also shown that CD1dKO mice control Aspergillus fumigatus infection poorly [26]. INKT cells produced IFNY activated by a combination of self-antigen recognition and IL-12 from antigen 
presenting cells (APCs). Production of IL-12 by APCs was induced through recognition of fungal cell wall $\beta-1,3$ glucans by Dectin-1, a C-type lectin receptor that binds this glycan.

\section{Protozoan parasite infections}

INKT cells also participate in immune response against some protozoan parasites. For example, Ja18KO mice showed increased parasite burden in skin lesions and draining lymph nodes after subcutaneous infection with Leishmania major, a cause of sand flytransmitted Leishmaniasis that ranges from cutaneous lesions to visceral infection. Decreased cytokine production, NK cell cytotoxicity and increased splenic parasite burden were seen in Ja18KO mice following intravenous infection, suggesting that $I$ NKT cells play important roles in host defense against $L$. major [27, 28]. In addition, CD1dKO mice were also shown to be more susceptible to L. donovani infection [29].

INKT cells are also involved in regulating excessive inflammation caused by parasite infection. Ja18KO mice developed severe inflammation in various organs, including spleen, liver and muscles, after Trypanosoma cruzi infection, causing a mouse model of Chagas disease, which is characterized by chronic inflammation in heart, gastrointestinal tract and nervous system. However, CD1dKO mice developed only mild inflammation, suggesting that different NKT cell subsets, type I and type II, exert different functions. If this were true, the most simple explanation would be that type II NKT cells expressing diverse TCR have pro-inflammatory functions, with $ı$ NKT cells having an anti-inflammatory function during T. cruzi infection [30]. However, because of the distortion in the Ja repertoire in Ja18KO mice noted above, further evidence will be required to confirm the counteracting effects of different CD1d-reactive populations.

\section{Viral infections}

INKT cells have also been shown to respond to viral infections, particularly when herpes family viruses are involved. For example, $ı$ NKT cells produce IFNy within $36 \mathrm{~h}$ of infection with mouse cytomegalovirus (MCMV), a $\beta$ herpes virus. This response was mediated by TLR9, IL-12 and IFNa/ $\beta$, but not by CD1d, showing that inflammatory signals independent of TCR engagement are sufficient in some contexts for the activation of $i$ NKT cells [31, 32]. IFNY producing NK cells and IFNY in blood were decreased in CD1dKO mice resulting in lower survival rates compared to WT mice. Interestingly, increased susceptibility to high dose MCMV infection was not seen in Ja18KO mice on the B6 background, although they had lower IFNY in blood compared to WT mice [32]. The discordant data in these two strains are subject to the interpretations discussed above. Interestingly, on the BALB/c background, Ja18KO do have higher viral plaque forming units in the spleen and liver at early times after infection (A. Tyznik, M. Kronenberg, C. Benedict, unpublished data). It is possible that $\mathrm{BALB} / \mathrm{c}$ mice, which lack the $\mathrm{Ly} 49 \mathrm{H}$ activating NK receptor that is so important for the response to MCMV [33,34], are more dependent on ${ }^{\mathrm{N} K T}$ cells than their B6 strain counterparts.

INKT cells play a protective role against genital HSV-2 infection through early production of IFNY [35], with CD1dKO mice being more susceptible to genital HSV-2 infection. $\mathrm{INKT}$ cells also are involved in controlling herpes simplex virus type 1 (HSV-1), as demonstrated by impaired viral clearance in both CD1dKO and Ja18KO mice [36]. However, the protective role of $i$ NKT cells in HSV-1 infection still remains uncertain, with other groups reporting similar susceptibility to HSV-1 infection between CD1dKO and WT mice [37]. Such discrepancies are common in studies of $i$ NKT cells in the context of other infections, including bacterial infections, for example infection with Pseudomonas aeruginosa [38, 39]. Discordant data have also been published for parasite infections, for example using Plasmodium species [40, 41]. These discrepancies may be due to differences in the strain, as 
illustrated above when considering the response to MCMV, the route of infection or dose, or intrinsic differences between inbred mouse colonies due to environmental differences, particularly variability in the microbiota.

\section{NNKT cells and infectious diseases in humans}

Several reports have indicated the possible important role of $i$ NKT cells in controlling viral infection in humans. INKT cells were reported to be reduced in number and function in patients with active Mycobacterium tuberculosis infection [42]. Considering viral infections, a girl who died after receiving the varicella vaccine was shown to have a defect in $I$ NKT cells and no other immune defects were observed [43]. Also, a life-threatening infection developed in boy given the varicella vaccine, and he was shown to be deficient for CD1d expression and $I$ NKT cells [44]. X-linked lymphoproliferative syndrome (XLP) patients have a mutation in a lymphocyte adaptor protein called signaling lymphocytic activation molecule associated protein (SAP). These individuals were shown to lack $I$ NKT cells, and the patients die from uncontrolled Epstein-Barr virus (EBV) infection $[45,46]$. Furthermore, some XLP patients have a mutation in the X-linked inhibitor of apoptosis (XIAP) gene but not in SAP also lack $I$ NKT cells. While these data suggest that $I$ NKT cells may have an important role in EBV infection [47], XLP patients have other immune defects.

Interestingly, several human viruses down regulate CD1d expression, including HSV-1, HIV and Kaposi sarcoma herpes virus [48] [49-52], suggestive of an immune evasion strategy. In summary, much of the data in humans are suggestive of a role for $\mathrm{NKT}$ cells in chronic viral infections. This is surprising considering the widely held view that $i$ NKT cells are early responders, but NK cells are also active in these infections and it is known that $\mathbb{N}$ NKT cells can participate in NK cell activation.

\section{NKT cells induce inflammation}

As mentioned earlier in this review, $₫$ NKT cells play a protective role in various microbial infections in mice. However, as noted in the discussion of Chlamydia infection, $\mathbb{I N K T}$ cells can also in some contexts contribute to immunopathology. Mice infected with Sendai virus developed chronic lung disease characterized by mucous cell metaplasia and airway hypersensitivity that resembles asthma and chronic obstructive pulmonary disease (COPD) in humans [53]. Macrophages are major sources of IL-13 after Sendai virus infection, and this disease was not observed in either IL-13KO or macrophage depleted mice. Interestingly, IL-13 producing $\mathrm{NKT}$ cells were increased in the lung at the chronic phase of Sendai virus infection, and INKT cells were shown to directly stimulate macrophages for IL-13 production [53]. Ja18KO and CD1dKO mice had reduced IL-13 producing macrophages, mucous cell metaplasia and airway hypersensitivity in lung. Moreover, $\mathrm{IL}-13^{+}$macrophages and $i$ NKT cells were increased in lungs from COPD patients compared to controls [53]. These data suggest that $\mathrm{NKT}$ cells participate in the pathogenesis of chronic inflammatory lung disease. INKT cells also participate in several models of sterile inflammation, such as ischemia reperfusion injury, but in some of these cases the inflammation is driven by $I$ NKT cell derived IFNY rather than IL-13 [54].

Although antimicrobial immune responses have been implicated in the induction of some autoimmune diseases, in most cases this has not been incontrovertibly demonstrated. Primary biliary cirrhosis (PBC) is characterized by immune-mediated destruction of the small bile ducts leading to bile extravasation, chronic inflammation and subsequent liver fibrosis. Essentially all PBC patients have signature autoantibodies against mitochondrial pyruvate dehydrogenase complex E2 (PDC-E2) that cross-react with the homologous enzyme of Novosphingobium aromaticivorans, a commensal bacterium in the intestine [55]. $N$. aromaticivorans infection in mice induces antibodies against microbial PDC-E2 that cross-react with the mitochondrial homologue, and that also induce chronic $\mathrm{T}$ cell mediated 
inflammation in small bile ducts [56]. The liver inflammation can be induced in recipient mice by transfer of CD4 and CD8 T cells, but not $ı$ NKT cells obtained from mice with the established liver disease, showing that autoreactive T cells mediate the inflammation. However, $ı$ NKT cells were required for the initiation of this disease [56]. It was previously shown that $\mathrm{NKT}$ cells were increased in the liver of PBC patients compared to healthy controls [57]. Collectively, these data indicate that $i$ NKT cell response to a commensal bacterium may play an important role in initiating autoimmunity in the liver.

\section{Intestinal microbes affect $\mathbb{N}$ NKT cell function}

Because $I$ NKT cells detect diverse microbes, it would seem likely that they are influenced by the content of commensal microbes. Although an early study indicated that $i$ NKT cells were not greatly diminished in number and function in germ free mice [58], more recent studies have shown that the intestinal microbiota has some effects on $i$ NKT cells. $\mathbb{N}$ NKT cells express diverse $V \beta$ rearrangements along with their invariant TCR a chain, but these involve predominantly V $\beta 8$, along with smaller contributions by V $\beta 7$ and V $\beta 2$. INKT cells isolated from specific pathogen free (SPF) mice obtained from different vendors showed differences in both the frequency of $i N K T$ cells expressing TCR VBT and their cytokine response to aGalCer. Additionally, $i$ NKT cells isolated from germ free mice had a less mature or activated phenotype, and fewer cells made cytokines including TNF, IFNy, IL-4 and IL-13 in response to aGalCer when compared to cells from SPF mice [59]. INKT cells isolated from mice deficient in either TLR signaling or IL-12 showed a normal phenotype and antigen response similar to SPF wild type mice, suggesting that the effect of intestinal microbiota on $I$ NKT cells is independent of inflammatory signals. Moreover, the immature phenotype of $\lambda$ NKT cells in germ-free mice was restored by intra-gastric injection of Sphingomonas bacteria, which possess $i$ NKT cell antigens, but not $E$. coli, which lack $I$ NKT cell antigens [59]. These data suggested that interaction of $I$ NKT cells with certain bacteria in the intestinal microbiota is critical for these cells to acquire a fully mature phenotype and function.

Germ-free mice and SPF mice born under germ-reduced conditions were shown to have an increased accumulation of $I$ NKT cells in the lamina propria and epithelium of the small and large intestine $[59,60]$ due to increased levels of the chemokine CXCL16 made by intestinal cells [60]. Germ-free mice exhibited a higher mortality in oxazolone-induced colitis [60]. Blocking CD1d with antibodies inhibited colitis, and an increased susceptibility to colitis was absent in $I$ NKT cell deficient germ free mice. These data are consistent with earlier work showing that oxazalone-induced colitis is dependent on ${ }_{\text {NKT }}$ cells, CD1d, and IL-13 [61]. Germ-free mice also showed an NKT cell accumulation in the lung, and these mice were more sensitive to allergic asthma [60]. Interestingly, exposure of neonatal mice, but not adult mice, to SPF conditions normalized the number of $i$ NKT cells in the colon and lung and in protection from increased colitis and asthma. Earlier work also showed that exposure of SPF suckling mice either to influenza virus, or to a glycolipid from Helicobacter pylori, the cause of most stomach ulcers, also would protect from asthma later in life [62]. The $H$. pylori glycolipid was shown to activate some $\mathrm{NKT}$ cells, and both the viral infection and the glycolipid caused changes in the $\mathrm{NKT}$ cell population that were correlated with asthma protection. Importantly, as with the germ free mice, the exposure to microbe (or the glycolipid) had to occur early in life in order for it to be protective long-term. These data are in line with the hygiene hypothesis, and they suggest that the activation of $I$ NKT cells early in life may play an important role in setting the inflammatory tone of the immune response.

\section{NNT cells recognize bacterial glycolipid antigens}

INKT cells can be activated to secrete cytokines such as IFNY by several pathways, including engagement of their TCR by foreign antigen, engagement by self-antigen, which 
usually also requires another signal delivered by a cytokine such as IL-12 from innate immune cells, a combination of cytokines alone, such as IL-12 and IL-18 in the absence of TCR engagement, or by engagement of activating NK receptors [63, 64]. Therefore, although $\mathrm{INKT}$ cells participate in the response to various microbes, it remained to be determined if they could recognize microbial glycolipid antigens with their TCR. Several microbial lipids, including phosphatidylinositol mannosides (PIMs) from Mycobacterium bovis bacillus Calmette Guérin, lipophosphoglycan from Leishmania donovani, a cholesterol-containing glycolipid from Helicobacter pylori and an antigen from $C$. muridarum were reported to activate $i$ NKT cells $[21,22,29,62,65]$. With the exception of the PIMs and the $H$. pylori antigen, the full structures of the antigens responsible are not known. Also, in several cases the compound in question may only activate a minority of the INKT cells, and because the a chain is invariant, this might reflect particular specificities imparted by the TCR $\beta$ rearrangement.

We and other groups have found that glycosphingolipids (GSLs) from Sphingomonas/ Novosphingobium bacteria are essentially universal antigens for $\mathrm{INKT}$ cells [66-68]. Sphingomonas GSLs containing either a galacturonic acid (GalA) or a glucuronic acid (GlcA) have structures similar to aGalCer (Figure 1). The in vitro experiments showed that the GSLs purified from Sphingomonas bacteria bound to CD1d and stimulated mouse 1 NKT cells to produce cytokines in a CD1d dependent manner. Both purified and synthetic Sphingomonas GSLs induced cytokine production by $I$ NKT cells in vivo. The $I$ NKT cell activation by Sphingomonas GSLs was also observed in mice deficient in TLR signaling or IL-12, showing that this activation was induced directly by recognition of Sphingomonas GSLs and not indirectly by cytokines and inflammation [66, 67]. Furthermore, CD1d tetramers loaded with Sphingomonas GSLs recognized a majority of mouse $I$ NKT cells [6668]. Human INKT cells from expanded lines recognized Sphingomonas GSLs and produced cytokines in a CD1d dependent manner, indicating the response is conserved. Furthermore, CD1d tetramers loaded with Sphingomonas GSLs recognized essentially all of the TCR ${ }^{+}$ cells in several human $\mathrm{NKT}$ cell lines cells [66, 67]. Sphingomonas bacteria are widely distributed in the environment [69], and have been detected as a commensal organism in some individuals [55], but the predominant glycosphingolipids in different Sphingomonas spp are not identical, and the subtle variations in lipid and carbohydrate structure can have a big influence on antigenic potency $[70,71]$.

Most bacteria do not produce glycosphingolipids, but Bacteroides spp. are a prevalent commensal organism of the human intestine, and many of them also have the capacity to produce sphingolipids. Recently, a glycosphingolipid antigen from Bacteroides fragilis has been purified and characterized and it also activates mouse and human $\mathrm{NKT}$ cells [72].

We identified glycolipids from the spirochete Borrelia burgdorferi, the first antigens that stimulate the population of $\mathbb{I N K T}$ cells that are derived from a pathogenic organism [73]. $B$. burgdorferi is a causative agent of Lyme disease, the most common tick-borne disease in North America and Europe. Lyme disease leads to diverse symptoms including inflammation in the joint, heart and nervous system. B. burgdorferi glycolipid-II (BbGL-II), one of two major glycolipids purified from B. burgdorferi [74], was shown to bind to CD1d and to stimulate mouse $I$ NKT cells in a CD1d dependent manner [73]. The structure of the B. burgdorferi antigen, called BbGL-II, is a a-galactosyl-diacylglycerol with a single alinked hexose sugar and two hydrophobic lipid tails. It is in this way similar to the Sphingomonas GalAGSL or aGalCer, although BbGL-II is a diacylglycerol, a different type of lipid from the ceramide lipids in glycosphingolipids (Figure 1). A synthetic version of the $B$. burgdorferi antigen, a glycolipid named BbGL-IIc, which contains a palmitic acid $\left(\mathrm{C}_{16: 0}\right)$ and an oleic acid $\left(\mathrm{C}_{18: 1}\right)$, two major fatty acids in $B$. burgdorferi, also stimulated the majority of mouse 1 NKT cells for cytokine release both in vitro and in vivo [73]. Although 
human ${ }_{\text {NKT }}$ cells also responded to $B$. burgdorferi glycolipids and they required glycolipids with more unsaturation in the fatty acids, such as BbGL-II containing a linoleic acid $\left(\mathrm{C}_{18: 2}\right)$ and an oleic acid $\left(\mathrm{C}_{18: 1}\right)$.

To determine if $I N K T$ cells also recognize antigens from pathogenic microbes that that cause widespread disease, we tested if $i$ NKT cells could recognize glycolipids from $S$. pneumoniae. This organism is estimated to cause $11 \%$ of all the deaths in children younger than 5 years old in the world [75]. As noted above, an effective host response of mice to $S$. pneumoniae is highly dependent on NKT cells. We found that $I$ NKT cells in the lung produce cytokines, including IFNY and IL-17, at the early phase of pulmonary infection with $S$. pneumoniae [18]. Cytokine production of $i$ NKT cells was inhibited by treatment with anti-CD1d antibodies, and CD11c $\mathrm{c}^{+}$DCs purified from $S$. pneumoniae infected mice stimulated mouse $\mathrm{N}$ NT hybridomas for cytokine production. These data suggested that

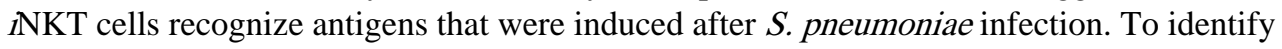
the antigen that $I$ NKT cells recognize during $S$. pneumoniae infection, we isolated two major glycolipids that are diacylglycerols containing either monosaccharide of glucose or disaccharides of galactose and glucose, and fatty acids of palmitic acid and vaccenic acid; vaccenic acid is rare in mammalian cells. The glucosyl-diacylglycerol (Glc-DAG) isolated from $S$. pneumoniae induced cytokine production by several $\mathrm{N}$ NKT hybridomas, but not hybridomas from type 2 NKT cells, in a CD1d dependent manner [18]. Like the other antigens identified, the $S$. pneumoniae Glc-DAG also induced cytokine production by $\mathrm{INKT}$ cells in vivo independent of TLR signaling and IL-12. By testing several synthetic versions of $S$. pneumoniae Glc-DAG containing different fatty acids, we determined that a synthetic version of the natural compound, which is Glc-DAG-s2 containing a palmitic acid in $s n-1$ position and a vaccenic acid in $s n-2$ position of the glycerol, is required (Figure 2).

Therefore, although the lipid tails are buried in the CD1d groove, there are precise structural requirements for the lipid because this determines not only the ability to bind to CD1d effectively, but also the orientation of the sugar that protrudes from the groove and which forms a major portion of the epitope recognized by the $i$ NKT cell TCR. Human $I$ NKT cells also produced cytokines in response to the purified $S$. pneumoniae Glc-DAG and Glc-DAGs2. Interestingly, group B Streptococcus (GBS), a leading causative agent of meningitis and sepsis in newborns has an antigen identical to Glc-DAG that stimulates INKT cells. These data show that $\mathbb{N}$ NKT cells recognize glycolipid antigens of certain pathogenic Gram-positive bacteria including $S$. pneumoniae and GBS.

INKT cell TCR-mediated recognition of these bacterial glycolipid antigens, including GalAGSL, BbGL-IIc and Glc-DAG-s2, was confirmed by binding studies using surface plasmon resonance (SPR), and also by determining the crystal structures of ternary complex of CD1d/bacterial antigen/INKT cell TCR [76, 77]. By comparing the structures of glycolipid antigen complexes with mouse CD1d, before and after TCR binding, we showed that $I$ NKT cell TCR binding caused a marked conformational change in the sugar and CD1d reorienting them to a conserved positioning that closely resembles the aGalCer complex with CD1d $[18,76,77,78]$. These data demonstrate that $I$ NKT cell TCR can reorient bacterial antigens to a preferred position for a conserved interaction.

\section{Recognition of bacterial antigens by INKT cells contributes to defense against bacterial infection}

NKT cells produce IFNY and IL-4 in the early phase of tick bite-infection with $B$. burgdorferi [79]. Most infected Ja18KO BALB/c mice could not eliminate bacteria from their tissues, and they exhibited more severe joint inflammation compared to WT mice. Ja18KO C57BL/6 mice also showed increased bacterial burden and inflammation in the heart compared to WT controls after B. burgdorferi infection [80]. On the C57BL/6 
background, $i$ NKT cells accumulated in the heart and produced IFN $\gamma$, that is important for bacterial clearance after $B$. burgdorferi infection. IFNY stimulated macrophages to increase cytokine production and phagocytosis of $B$. burgdorferi spirochetes [80]. Furthermore, the $I$ NKT cell response to $B$. burgdorferi in the liver was visualized directly by intravital spinning-disk microscopy. Following intravenous B. burgdorferi infection, Kupffer cells in the liver sinusoids captured the bacteria [81]. $I$ NKT cells patrolling the liver sinusoids [82] formed a cluster on the B. burgdorferi injected Kupffer cells which led to IFNy production and elimination of bacteria in a CD1d and CXCR3 dependent manner [81]. In the absence of INKT cells, Borrelia spirochetes were greatly increased in the joint tissue. Collectively, these findings suggest that $\mathrm{NKT}$ cells can enhance bacterial clearance and prevent inflammation in the joint and heart of $B$. burgdorferi infected mice through recognition of bacterial antigens.

Ja18KO and CD1dKO mice also are more susceptible to $S$. pneumoniae infection [15, 83]. We tested if blocking antigen recognition by $\mathrm{NKT}$ cells would affect bacterial clearance. Bacterial loads in lungs were significantly increased in mice treated with anti-CD1d antibodies compared to controls [18]. These data show that recognition of glycolipid antigens by the $i$ NKT cell TCR plays an important role in the clearance of $S$. pneumoniae. It was also shown that IL-12 presumably from TLR stimulated APCs is important for IFNY production by $I$ NKT cells during $S$. pneumoniae infection $[18,83]$. These data have contributed to the hypothesis that self-antigen presentation is important even in those infections, such as $S$. pneumoniae, in which the invading microbe expresses a foreign antigen. While the recognition of foreign and self-antigens are not mutually exclusive, there is no reason why the need for an additional signal provided by IL-12 cannot apply equally to foreign as well as self antigens. Furthermore, it seems unlikely that abundant glycolipid antigens for $I$ NKT cells, amounting to more than $40 \%$ of the lipids in the case of $S$. pneumoniae, do not participate in $\mathrm{INKT}$ cell activation. Collectively, the data suggest that recognition of bacterial glycolipid antigens by $\AA_{\mathrm{NKT}}$ cells is very useful to detect certain bacteria in addition to the classical TLR mediated detection of microbial associated molecular patterns. Recognition of these bacteria by the invariant TCR of $i$ NKT cells is conserved between rodents and mammals, indicating that $\mathrm{NKT}$ cells are evolutionally conserved because these cells are important in detecting certain pathogenic microbes.

\section{Conclusions}

Effective vaccines are useful for preventing infectious diseases. Glycolipid mediated $I$ NKT cell activation induces stimulation of DCs and other innate immune cells, including NK cells, leading to enhanced acquired immunity (Figure 2). Several reports indicate that $\mathrm{NKT}$ cell activation may be applied to induce effective adjuvant activity. Intranasal coadministration of aGalCer and either influenza vaccine or inactivated virus induced protection of mice from lethal challenge with influenza [84-86]. The mice vaccinated with aGalCer and either influenza vaccine or inactivated virus also exhibited increased antibody titers and generation of memory CTL [84-87]. Glycolipid mediated INKT cell activation has also been shown to enhance the protective effect of vaccines against malaria and genital HSV-2 infection [88, 89]. Therefore we suggest that the adjuvant effect mediated by $\mathbb{N}$ NKT cells may be applicable to vaccines for various infections and may be useful for designing new types of vaccines for humans.

\section{Acknowledgments}

This work was supported by the US National Institutes of Health grants (AI45053, AI69296, AI71922 to M.K.), the Japan Society for the Promotion of Science and Ministry of Education, Culture, Sports, Science and Technology (25713038), the Ministry of Health, Labor and Welfare of Japan (H25-shinkou-wakate-005), the Mochida 
Memorial Foundation for Medical and Pharmaceutical Research, Takeda Science Foundation and Kato Memorial Bioscience Foundation (to Y.K.).

\section{References}

1. Tupin E, Kinjo Y, Kronenberg M. The unique role of natural killer T cells in the response to microorganisms. Nat Rev Microbiol. 2007; 5:405-17. [PubMed: 17487145]

2. Taniguchi M, Tashiro T, Dashtsoodol N, Hongo N, Watarai H. The specialized iNKT cell system recognizes glycolipid antigens and bridges the innate and acquired immune systems with potential applications for cancer therapy. Int Immunol. 2010; 22:1-6. [PubMed: 19858073]

3. Brigl M, Brenner MB. How invariant natural killer T cells respond to infection by recognizing microbial or endogenous lipid antigens. Semin Immunol. 2010; 22:79-86. [PubMed: 19948416]

4. Pei B, Vela JL, Zajonc D, Kronenberg M. Interplay between carbohydrate and lipid in recognition of glycolipid antigens by natural killer T cells. Ann N Y Acad Sci. 2012; 1253:68-79. [PubMed: 22352829]

5. Rossjohn J, Pellicci DG, Patel O, Gapin L, Godfrey DI. Recognition of CD1d-restricted antigens by natural killer T cells. Nat Rev Immunol. 2012; 12:845-57. [PubMed: 23154222]

6. Zajonc DM, Kronenberg M. Carbohydrate specificity of the recognition of diverse glycolipids by natural killer T cells. Immunol Rev. 2009; 230:188-200. [PubMed: 19594637]

7. Godfrey DI, MacDonald HR, Kronenberg M, Smyth MJ, Van Kaer L. NKT cells: what's in a name? Nat Rev Immunol. 2004; 4:231-7. [PubMed: 15039760]

8. Kawano T, Cui J, Koezuka Y, Toura I, Kaneko Y, Motoki K, et al. CD1d-restricted and TCRmediated activation of valpha14 NKT cells by glycosylceramides. Science. 1997; 278:1626-9. [PubMed: 9374463]

9. Brossay L, Chioda M, Burdin N, Koezuka Y, Casorati G, Dellabona P, et al. CD1d-mediated recognition of an alpha-galactosylceramide by natural killer $\mathrm{T}$ cells is highly conserved through mammalian evolution. J Exp Med. 1998; 188:1521-8. [PubMed: 9782129]

10. Jahng A, Maricic I, Aguilera C, Cardell S, Halder RC, Kumar V. Prevention of autoimmunity by targeting a distinct, noninvariant CD1d-reactive $\mathrm{T}$ cell population reactive to sulfatide. $\mathrm{J}$ Exp Med. 2004; 199:947-57. [PubMed: 15051763]

11. Terabe M, Swann J, Ambrosino E, Sinha P, Takaku S, Hayakawa Y, et al. A nonclassical nonValpha14Jalpha18 CD1d-restricted (type II) NKT cell is sufficient for down-regulation of tumor immunosurveillance. J Exp Med. 2005; 202:1627-33. [PubMed: 16365146]

12. Rhost S, Lofbom L, Rynmark BM, Pei B, Mansson JE, Teneberg S, et al. Identification of novel glycolipid ligands activating a sulfatide-reactive, CD1d-restricted, type II natural killer T lymphocyte. Eur J Immunol. 2012; 42:2851-60. [PubMed: 22777932]

13. Tatituri RV, Watts GF, Bhowruth V, Barton N, Rothchild A, Hsu FF, et al. Recognition of microbial and mammalian phospholipid antigens by NKT cells with diverse TCRs. Proc Natl Acad Sci U S A. 2013; 110:1827-32. [PubMed: 23307809]

14. Cui J, Shin T, Kawano T, Sato H, Kondo E, Toura I, et al. Requirement for Valpha14 NKT cells in IL-12-mediated rejection of tumors. Science. 1997; 278:1623-6. [PubMed: 9374462]

15. Kawakami K, Yamamoto N, Kinjo Y, Miyagi K, Nakasone C, Uezu K, et al. Critical role of Valpha14+ natural killer T cells in the innate phase of host protection against Streptococcus pneumoniae infection. Eur J Immunol. 2003; 33:3322-30. [PubMed: 14635040]

16. Nakamatsu M, Yamamoto N, Hatta M, Nakasone C, Kinjo T, Miyagi K, et al. Role of interferongamma in Valpha14+ natural killer T cell-mediated host defense against Streptococcus pneumoniae infection in murine lungs. Microbes Infect. 2007; 9:364-74. [PubMed: 17314060]

17. Bedel R, Matsuda JL, Brigl M, White J, Kappler J, Marrack P, et al. Lower TCR repertoire diversity in Traj18-deficient mice. Nat Immunol. 2012; 13:705-6. [PubMed: 22814339]

18. Kinjo Y, Illarionov P, Vela JL, Pei B, Girardi E, Li X, et al. Invariant natural killer T cells recognize glycolipids from pathogenic Gram-positive bacteria. Nat Immunol. 2011; 12:966-74. [PubMed: 21892173] 
19. Joyee AG, Qiu H, Wang S, Fan Y, Bilenki L, Yang X. Distinct NKT cell subsets are induced by different Chlamydia species leading to differential adaptive immunity and host resistance to the infections. J Immunol. 2007; 178:1048-58. [PubMed: 17202368]

20. Joyee AG, Uzonna J, Yang X. Invariant NKT cells preferentially modulate the function of CD8 alpha+ dendritic cell subset in inducing type 1 immunity against infection. J Immunol. 2010; 184:2095-106. [PubMed: 20089704]

21. Peng Y, Zhao L, Shekhar S, Liu L, Wang H, Chen Q, et al. The glycolipid exoantigen derived from Chlamydia muridarum activates invariant natural killer T cells. Cell Mol Immunol. 2012; 9:361-6. [PubMed: 22728762]

22. Jiang J, Karimi O, Ouburg S, Champion CI, Khurana A, Liu G, et al. Interruption of CXCL13CXCR5 axis increases upper genital tract pathology and activation of NKT cells following chlamydial genital infection. PLoS One. 2012; 7:e47487. [PubMed: 23189125]

23. Kawana K, Quayle AJ, Ficarra M, Ibana JA, Shen L, Kawana Y, et al. CD1d degradation in Chlamydia trachomatis-infected epithelial cells is the result of both cellular and chlamydial proteasomal activity. J Biol Chem. 2007; 282:7368-75. [PubMed: 17215251]

24. Wong CH, Jenne CN, Lee WY, Leger C, Kubes P. Functional innervation of hepatic iNKT cells is immunosuppressive following stroke. Science. 2011; 334:101-5. [PubMed: 21921158]

25. Kawakami K, Kinjo Y, Uezu K, Yara S, Miyagi K, Koguchi Y, et al. Monocyte chemoattractant protein-1-dependent increase of $\mathrm{V}$ alpha 14 NKT cells in lungs and their roles in Th1 response and host defense in cryptococcal infection. J Immunol. 2001; 167:6525-32. [PubMed: 11714821]

26. Cohen NR, Tatituri RV, Rivera A, Watts GF, Kim EY, Chiba A, et al. Innate recognition of cell wall beta-glucans drives invariant natural killer $\mathrm{T}$ cell responses against fungi. Cell Host Microbe. 2011; 10:437-50. [PubMed: 22100160]

27. Ishikawa H, Hisaeda H, Taniguchi M, Nakayama T, Sakai T, Maekawa Y, et al. CD4(+) $\mathrm{v}$ (alpha)14 NKT cells play a crucial role in an early stage of protective immunity against infection with Leishmania major. Int Immunol. 2000; 12:1267-74. [PubMed: 10967021]

28. Mattner J, Donhauser N, Werner-Felmayer G, Bogdan C. NKT cells mediate organ-specific resistance against Leishmania major infection. Microbes Infect. 2006; 8:354-62. [PubMed: 16239118]

29. Amprey JL, Im JS, Turco SJ, Murray HW, Illarionov PA, Besra GS, et al. A subset of liver NK T cells is activated during Leishmania donovani infection by CD1d-bound lipophosphoglycan. J Exp Med. 2004; 200:895-904. [PubMed: 15466622]

30. Duthie MS, Kahn M, White M, Kapur RP, Kahn SJ. Critical proinflammatory and antiinflammatory functions of different subsets of CD1d-restricted natural killer T cells during Trypanosoma cruzi infection. Infect Immun. 2005; 73:181-92. [PubMed: 15618153]

31. Tyznik AJ, Tupin E, Nagarajan NA, Her MJ, Benedict CA, Kronenberg M. Cutting edge: the mechanism of invariant NKT cell responses to viral danger signals. J Immunol. 2008; 181:4452-6. [PubMed: 18802047]

32. Wesley JD, Tessmer MS, Chaukos D, Brossay L. NK cell-like behavior of Valpha14i NK T cells during MCMV infection. PLoS Pathog. 2008; 4:e1000106. [PubMed: 18636102]

33. Lee SH, Girard S, Macina D, Busa M, Zafer A, Belouchi A, et al. Susceptibility to mouse cytomegalovirus is associated with deletion of an activating natural killer cell receptor of the Ctype lectin superfamily. Nat Genet. 2001; 28:42-5. [PubMed: 11326273]

34. Daniels KA, Devora G, Lai WC, O’Donnell CL, Bennett M, Welsh RM. Murine cytomegalovirus is regulated by a discrete subset of natural killer cells reactive with monoclonal antibody to Ly49H. J Exp Med. 2001; 194:29-44. [PubMed: 11435470]

35. Ashkar AA, Rosenthal KL. Interleukin-15 and natural killer and NKT cells play a critical role in innate protection against genital herpes simplex virus type 2 infection. J Virol. 2003; 77:10168-71. [PubMed: 12941930]

36. Grubor-Bauk B, Simmons A, Mayrhofer G, Speck PG. Impaired clearance of herpes simplex virus type 1 from mice lacking CD1d or NKT cells expressing the semivariant V alpha 14-J alpha 281 TCR. J Immunol. 2003; 170:1430-4. [PubMed: 12538704]

37. Cornish AL, Keating R, Kyparissoudis K, Smyth MJ, Carbone FR, Godfrey DI. NKT cells are not critical for HSV-1 disease resolution. Immunol Cell Biol. 2006; 84:13-9. [PubMed: 16277640] 
38. Nieuwenhuis EE, Matsumoto T, Exley M, Schleipman RA, Glickman J, Bailey DT, et al. CD1ddependent macrophage-mediated clearance of Pseudomonas aeruginosa from lung. Nat Med. 2002; 8:588-93. [PubMed: 12042809]

39. Kinjo T, Nakamatsu M, Nakasone C, Yamamoto N, Kinjo Y, Miyagi K, et al. NKT cells play a limited role in the neutrophilic inflammatory responses and host defense to pulmonary infection with Pseudomonas aeruginosa. Microbes Infect. 2006; 8:2679-85. [PubMed: 16979364]

40. Mannoor MK, Weerasinghe A, Halder RC, Reza S, Morshed M, Ariyasinghe A, et al. Resistance to malarial infection is achieved by the cooperation of NK1.1(+) and NK1. 1(-) subsets of intermediate TCR cells which are constituents of innate immunity. Cell Immunol. 2001; 211:96104. [PubMed: 11591113]

41. Hansen DS, Siomos MA, Buckingham L, Scalzo AA, Schofield L. Regulation of murine cerebral malaria pathogenesis by CD1d-restricted NKT cells and the natural killer complex. Immunity. 2003; 18:391-402. [PubMed: 12648456]

42. Kee SJ, Kwon YS, Park YW, Cho YN, Lee SJ, Kim TJ, et al. Dysfunction of natural killer T cells in patients with active Mycobacterium tuberculosis infection. Infect Immun. 2012; 80:2100-8. [PubMed: 22409933]

43. Levy O, Orange JS, Hibberd PS, Steinberg S, LaRussa P, Weinberg A, et al. Disseminated varicella infection due to the vaccine strain of varicella-zoster virus, in a patient with a novel deficiency in natural killer T cells. J Infect Dis. 2003; 188:948-53. [PubMed: 14513412]

44. Banovic T, Yanilla M, Simmons R, Robertson I, Schroder WA, Raffelt NC, et al. Disseminated varicella infection caused by varicella vaccine strain in a child with low invariant natural killer $\mathrm{T}$ cells and diminished CD1d expression. J Infect Dis. 2011; 204:1893-901. [PubMed: 22043019]

45. Pasquier B, Yin L, Fondaneche MC, Relouzat F, Bloch-Queyrat C, Lambert N, et al. Defective NKT cell development in mice and humans lacking the adapter SAP, the X-linked lymphoproliferative syndrome gene product. J Exp Med. 2005; 201:695-701. [PubMed: 15738056]

46. Nichols KE, Hom J, Gong SY, Ganguly A, Ma CS, Cannons JL, et al. Regulation of NKT cell development by SAP, the protein defective in XLP. Nat Med. 2005; 11:340-5. [PubMed: 15711562]

47. Rigaud S, Fondaneche MC, Lambert N, Pasquier B, Mateo V, Soulas P, et al. XIAP deficiency in humans causes an X-linked lymphoproliferative syndrome. Nature. 2006; 444:110-4. [PubMed: 17080092]

48. Yuan W, Dasgupta A, Cresswell P. Herpes simplex virus evades natural killer T cell recognition by suppressing CD1d recycling. Nat Immunol. 2006; 7:835-42. [PubMed: 16845396]

49. Rao P, Pham HT, Kulkarni A, Yang Y, Liu X, Knipe DM, et al. Herpes simplex virus 1 glycoprotein B and US3 collaborate to inhibit CD1d antigen presentation and NKT cell function. $\mathrm{J}$ Virol. 2011; 85:8093-104. [PubMed: 21653669]

50. Hage CA, Kohli LL, Cho S, Brutkiewicz RR, Twigg HL 3rd, Knox KS. Human immunodeficiency virus gp120 downregulates CD1d cell surface expression. Immunol Lett. 2005; 98:131-5. [PubMed: 15790518]

51. Chen N, McCarthy C, Drakesmith H, Li D, Cerundolo V, McMichael AJ, et al. HIV-1 downregulates the expression of CD1d via Nef. Eur J Immunol. 2006; 36:278-86. [PubMed: 16385629]

52. Sanchez DJ, Gumperz JE, Ganem D. Regulation of CD1d expression and function by a herpesvirus infection. J Clin Invest. 2005; 115:1369-78. [PubMed: 15864354]

53. Kim EY, Battaile JT, Patel AC, You Y, Agapov E, Grayson MH, et al. Persistent activation of an innate immune response translates respiratory viral infection into chronic lung disease. Nat Med. 2008; 14:633-40. [PubMed: 18488036]

54. Lappas CM, Day YJ, Marshall MA, Engelhard VH, Linden J. Adenosine A2A receptor activation reduces hepatic ischemia reperfusion injury by inhibiting CD1d-dependent NKT cell activation. J Exp Med. 2006; 203:2639-48. [PubMed: 17088433]

55. Selmi C, Balkwill DL, Invernizzi P, Ansari AA, Coppel RL, Podda M, et al. Patients with primary biliary cirrhosis react against a ubiquitous xenobiotic-metabolizing bacterium. Hepatology. 2003; 38:1250-7. [PubMed: 14578864] 
56. Mattner J, Savage PB, Leung P, Oertelt SS, Wang V, Trivedi O, et al. Liver autoimmunity triggered by microbial activation of natural killer T cells. Cell Host Microbe. 2008; 3:304-15. [PubMed: 18474357]

57. Kita H, Naidenko OV, Kronenberg M, Ansari AA, Rogers P, He XS, et al. Quantitation and phenotypic analysis of natural killer T cells in primary biliary cirrhosis using a human CD1d tetramer. Gastroenterology. 2002; 123:1031-43. [PubMed: 12360465]

58. Park SH, Benlagha K, Lee D, Balish E, Bendelac A. Unaltered phenotype, tissue distribution and function of Valpha14(+) NKT cells in germ-free mice. Eur J Immunol. 2000; 30:620-5. [PubMed: 10671219]

59. Wingender G, Stepniak D, Krebs P, Lin L, McBride S, Wei B, et al. Intestinal microbes affect phenotypes and functions of invariant natural killer T cells in mice. Gastroenterology. 2012; 143:418-28. [PubMed: 22522092]

60. Olszak T, An D, Zeissig S, Vera MP, Richter J, Franke A, et al. Microbial exposure during early life has persistent effects on natural killer T cell function. Science. 2012; 336:489-93. [PubMed: 22442383]

61. Heller F, Fuss IJ, Nieuwenhuis EE, Blumberg RS, Strober W. Oxazolone colitis, a Th2 colitis model resembling ulcerative colitis, is mediated by IL-13-producing NK-T cells. Immunity. 2002; 17:629-38. [PubMed: 12433369]

62. Chang YJ, Kim HY, Albacker LA, Lee HH, Baumgarth N, Akira S, et al. Influenza infection in suckling mice expands an NKT cell subset that protects against airway hyperreactivity. J Clin Invest. 2011; 121:57-69. [PubMed: 21157038]

63. Brigl M, Bry L, Kent SC, Gumperz JE, Brenner MB. Mechanism of CD1d-restricted natural killer T cell activation during microbial infection. Nat Immunol. 2003; 4:1230-7. [PubMed: 14578883]

64. Nagarajan NA, Kronenberg M. Invariant NKT cells amplify the innate immune response to lipopolysaccharide. J Immunol. 2007; 178:2706-13. [PubMed: 17312112]

65. Fischer K, Scotet E, Niemeyer M, Koebernick H, Zerrahn J, Maillet S, et al. Mycobacterial phosphatidylinositol mannoside is a natural antigen for CD1d-restricted T cells. Proc Natl Acad Sci U S A. 2004; 101:10685-90. [PubMed: 15243159]

66. Kinjo Y, Wu D, Kim G, Xing GW, Poles MA, Ho DD, et al. Recognition of bacterial glycosphingolipids by natural killer T cells. Nature. 2005; 434:520-5. [PubMed: 15791257]

67. Mattner J, Debord KL, Ismail N, Goff RD, Cantu C 3rd, Zhou D, et al. Exogenous and endogenous glycolipid antigens activate NKT cells during microbial infections. Nature. 2005; 434:525-9. [PubMed: 15791258]

68. Sriram V, Du W, Gervay-Hague J, Brutkiewicz RR. Cell wall glycosphingolipids of Sphingomonas paucimobilis are CD1d-specific ligands for NKT cells. Eur J Immunol. 2005; 35:1692-701. [PubMed: 15915536]

69. Neef A, Witzenberger R, Kampfer P. Detection of sphingomonads and in situ identification in activated sludge using 16S rRNA-targeted oligonucleotide probes. J Ind Microbiol Biotechnol. 1999; 23:261-267. [PubMed: 11423942]

70. Long X, Deng S, Mattner J, Zang Z, Zhou D, McNary N, et al. Synthesis and evaluation of stimulatory properties of Sphingomonadaceae glycolipids. Nat Chem Biol. 2007; 3:559-64. [PubMed: 17660835]

71. Kinjo Y, Pei B, Bufali S, Raju R, Richardson SK, Imamura M, et al. Natural Sphingomonas glycolipids vary greatly in their ability to activate natural killer T cells. Chem Biol. 2008; 15:65464. [PubMed: 18635002]

72. Brown LCW, Penaranda C, Kashyap PC, Williams BB, Clardy J, Kronenberg M, et al. Production of an NKT cell stimulatory glycosphingolipid by a prominent member of the human gut microbiota. PLoS Biol. in press.

73. Kinjo Y, Tupin E, Wu D, Fujio M, Garcia-Navarro R, Benhnia MR, et al. Natural killer T cells recognize diacylglycerol antigens from pathogenic bacteria. Nat Immunol. 2006; 7:978-86. [PubMed: 16921381]

74. Ben-Menachem G, Kubler-Kielb J, Coxon B, Yergey A, Schneerson R. A newly discovered cholesteryl galactoside from Borrelia burgdorferi. Proc Natl Acad Sci U S A. 2003; 100:7913-8. [PubMed: 12799465] 
75. O’Brien KL, Wolfson LJ, Watt JP, Henkle E, Deloria-Knoll M, McCall N, et al. Burden of disease caused by Streptococcus pneumoniae in children younger than 5 years: global estimates. Lancet. 2009; 374:893-902. [PubMed: 19748398]

76. Li Y, Girardi E, Wang J, Yu ED, Painter GF, Kronenberg M, et al. The Valpha14 invariant natural killer T cell TCR forces microbial glycolipids and CD1d into a conserved binding mode. J Exp Med. 2010; 207:2383-93. [PubMed: 20921281]

77. Girardi E, Yu ED, Li Y, Tarumoto N, Pei B, Wang J, et al. Unique interplay between sugar and lipid in determining the antigenic potency of bacterial antigens for NKT cells. PLoS Biol. 2011; 9:e1001189. [PubMed: 22069376]

78. Wu D, Zajonc DM, Fujio M, Sullivan BA, Kinjo Y, Kronenberg M, et al. Design of natural killer T cell activators: Structure and function of a microbial glycosphingolipid bound to mouse CD1d. Proc Natl Acad Sci U S A. 2006; 103:3972-7. [PubMed: 16537470]

79. Tupin E, Benhnia MR, Kinjo Y, Patsey R, Lena CJ, Haller MC, et al. NKT cells prevent chronic joint inflammation after infection with Borrelia burgdorferi. Proc Natl Acad Sci U S A. 2008; 105:19863-8. [PubMed: 19060201]

80. Olson CM Jr, Bates TC, Izadi H, Radolf JD, Huber SA, Boyson JE, et al. Local production of IFNgamma by invariant NKT cells modulates acute Lyme carditis. J Immunol. 2009; 182:3728-34. [PubMed: 19265151]

81. Lee WY, Moriarty TJ, Wong CH, Zhou H, Strieter RM, van Rooijen N, et al. An intravascular immune response to Borrelia burgdorferi involves Kupffer cells and iNKT cells. Nat Immunol. 2010; 11:295-302. [PubMed: 20228796]

82. Geissmann F, Cameron TO, Sidobre S, Manlongat N, Kronenberg M, Briskin MJ, et al. Intravascular immune surveillance by CXCR6+ NKT cells patrolling liver sinusoids. PLoS Biol. 2005; 3:e113. [PubMed: 15799695]

83. Brigl M, Tatituri RV, Watts GF, Bhowruth V, Leadbetter EA, Barton N, et al. Innate and cytokinedriven signals, rather than microbial antigens, dominate in natural killer $\mathrm{T}$ cell activation during microbial infection. J Exp Med. 2011; 208:1163-77. [PubMed: 21555485]

84. Ko SY, Ko HJ, Chang WS, Park SH, Kweon MN, Kang CY. alpha- Galactosylceramide can act as a nasal vaccine adjuvant inducing protective immune responses against viral infection and tumor. $\mathrm{J}$ Immunol. 2005; 175:3309-17. [PubMed: 16116223]

85. Youn HJ, Ko SY, Lee KA, Ko HJ, Lee YS, Fujihashi K, et al. A single intranasal immunization with inactivated influenza virus and alpha-galactosylceramide induces long-term protective immunity without redirecting antigen to the central nervous system. Vaccine. 2007; 25:5189-98. [PubMed: 17548137]

86. Kamijuku H, Nagata Y, Jiang X, Ichinohe T, Tashiro T, Mori K, et al. Mechanism of NKT cell activation by intranasal coadministration of alpha-galactosylceramide, which can induce crossprotection against influenza viruses. Mucosal Immunol. 2008; 1:208-18. [PubMed: 19079180]

87. Guillonneau C, Mintern JD, Hubert FX, Hurt AC, Besra GS, Porcelli S, et al. Combined NKT cell activation and influenza virus vaccination boosts memory CTL generation and protective immunity. Proc Natl Acad Sci U S A. 2009; 106:3330-5. [PubMed: 19211791]

88. Li X, Fujio M, Imamura M, Wu D, Vasan S, Wong CH, et al. Design of a potent CD1d-binding NKT cell ligand as a vaccine adjuvant. Proc Natl Acad Sci U S A. 2010; 107:13010-5. [PubMed: 20616071]

89. Lindqvist M, Persson J, Thorn K, Harandi AM. The mucosal adjuvant effect of alphagalactosylceramide for induction of protective immunity to sexually transmitted viral infection. J Immunol. 2009; 182:6435-43. [PubMed: 19414797] 
«GalCer

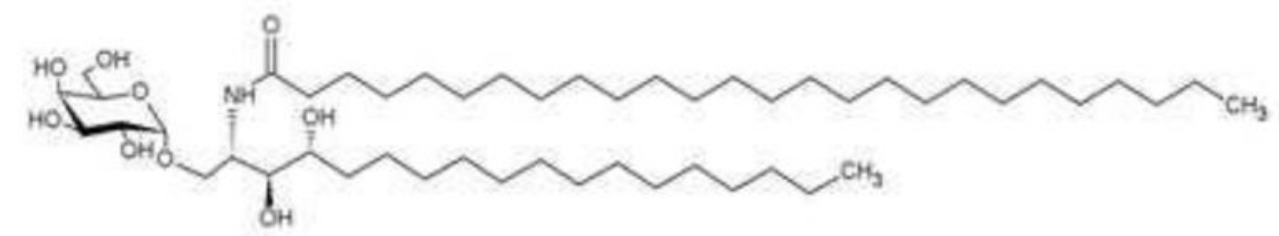

GaIAGSL

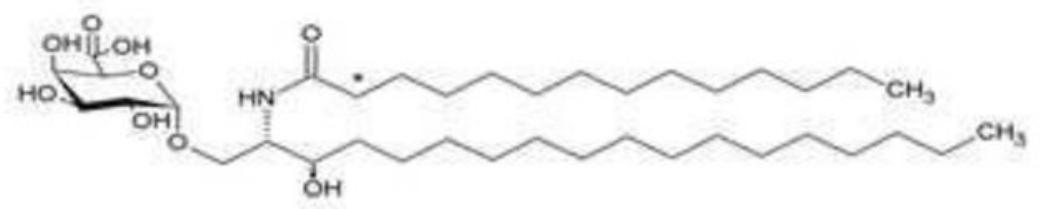

GICAGSL

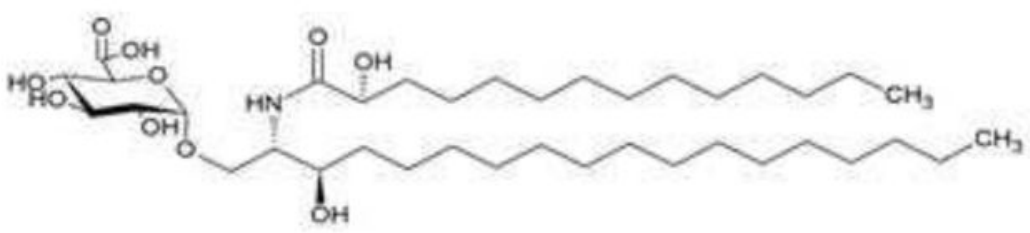

BbGL-IIc

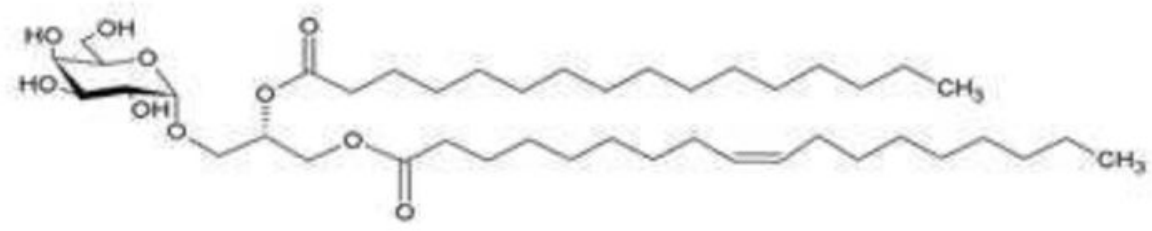

Glc-DAG-s2

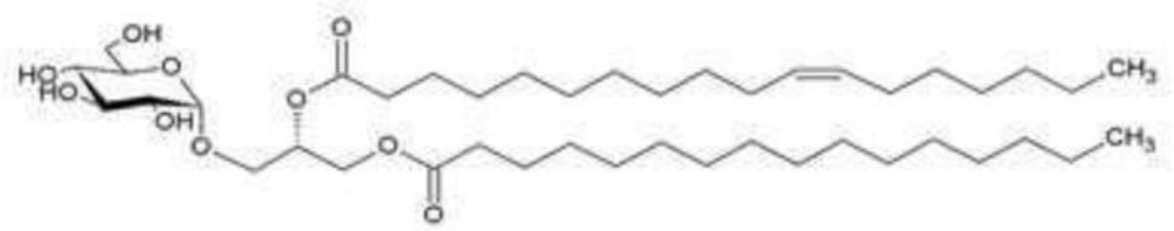

Figure 1. Structures of the glycolipid antigens for $i$ NKT cells

Structures of aGalCer, galacturonic acid (GalA) containing glycosphingolipid (GalAGSL) and glucuronic acid (GlcA) containing GSL (GlcAGSL) from Sphingomonas bacteria, Borrelia burgdorferi glycolipid (BbGL)-IIc, and glucosyl-diacylglycerol (Glc-DAG-s2) from Streptococcus pneumoniae are shown. The asterisk indicates that the 2-hydroxyl on the acyl chain of GalAGSL is sometimes present in bacteria. 


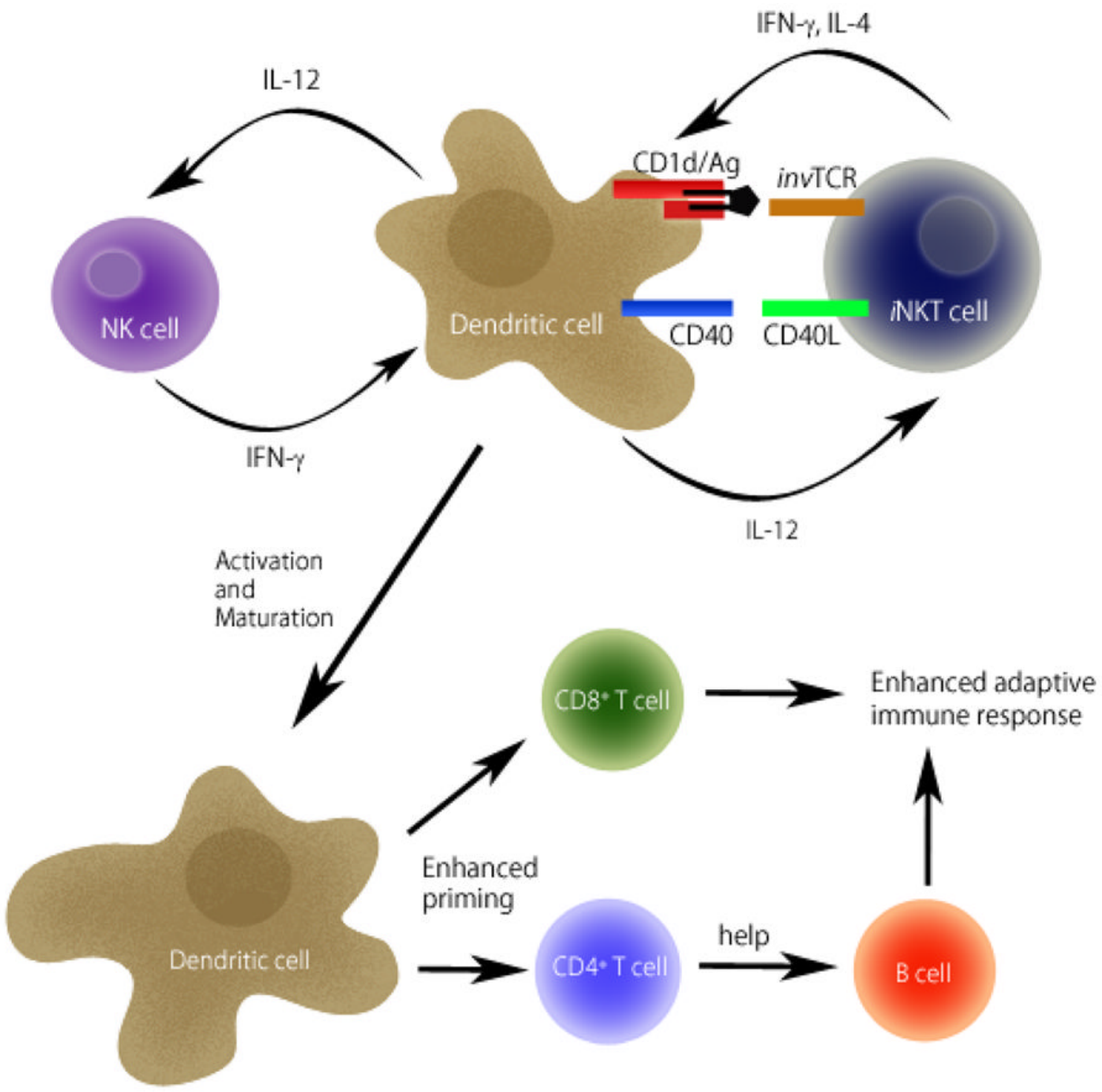

Figure 2. $i$ NKT cell activation augments innate and acquired immunity Upon activation through recognition of glycolipid antigens (Ag) presented by CD1d molecules on DCs, INKT cells start to express CD40L and produce IFNY and IL-4.

Subsequently, activated $I$ NKT cells promote activation of DCs through cytokines and the CD40-CD40L interaction. In return, DCs secrete IL-12, which stimulates IFNy production by $\mathrm{INKT}$ cells and NK cells, leading to further stimulation of DCs in a positive feedback loop. DC activation induces maturation leading to enhanced priming of CD4 and CD8 T cells. CD4 T cells provide help to B cells for antibody production. Collectively, $I$ NKT cell activation augments both innate and acquired immunity. 